\title{
An Analysis of an Inventory of Community Resilience Frameworks
}

\author{
Jarrod Loerzel and Maria Dillard \\ National Institute of Standards and Technology, \\ Gaithersburg, MD 20899, USA
}

jarrod.loerzel@nist.gov

maria.dillard@nist.gov

Data DOI: https://doi.org/10.18434/mds2-2297

Key words: assessment methodology; community resilience; indicators; resilience frameworks.

Accepted: August 20, 2021

Published: October 20, 2021

https://doi.org/10.6028/jres.126.031

\section{Summary}

While resilience is a concept that has many definitions [1-8], the National Institute of Standards and Technology (NIST) and other federal agencies have adopted the definition of resilience as proposed in the 2013 Presidential Policy Directive 21 which states that resilience is "the ability to prepare for anticipated hazards, adapt to changing conditions, and withstand and recover rapidly from disruptions" [8]. However, a missing accompanying element to this definition is the way in which resilience is to be measured. In response, there is a growing field of research focused on community-level resilience; academic, governmental, and private sector researchers have developed and examined approaches to measure the concept both quantitatively and qualitatively.

As a result, frameworks have been developed to connect concepts of resilience to measurable indicators and/or measures to operationalize the concept of resilience. They have emerged both as a methodology to study community resilience and as a decision support tool for disaster and adaptation planning. However, reviews by the NIST Community Resilience Program [9-12] and others [13-16] have shown that there is a lack of consensus in terms of the theoretical approaches taken, indicators and measures used, data requirements, and spatial scales among the frameworks. To better understand these disparities, NIST constructed an inventory of resilience frameworks.

This data article provides details of an analysis of an inventory of 56 community resilience frameworks. In this article, a description of how the inventory data was catalogued is presented. Section 3 outlines the categories used to analyze the frameworks as well as the categories used to bin the indicators and measures used in each. Section 3.1 describes the results of the categorization process for the 56 resilience frameworks. Section 3.2 outlines the results of the categorization of the 3,298 indicators used in each framework. Section 3.3 describes the 7,165 measures used in the 56 frameworks. 


\section{Journal of Research of the National Institute of Standards and Technology}

\section{Data Specifications}

\begin{tabular}{ll}
\hline NIST Operating Unit(s) & Engineering Laboratory, Materials and Structural Systems Division \\
\hline Format & Tabular data file (.xls) \\
\hline Instrument & $\mathrm{N} / \mathrm{A}$ \\
\hline $\begin{array}{l}\text { Spatial or Temporal } \\
\text { Elements }\end{array}$ & $\mathrm{N} / \mathrm{A}$ \\
\hline Data Dictionary & $\mathrm{https} / /$ data.nist.gov/od/id/mds2-2297 \\
\hline Accessibility & $\begin{array}{l}\text { All datasets submitted to Journal of Research of NIST are publicly } \\
\text { available. }\end{array}$ \\
\hline License & https://www.nist.gov/director/licensing \\
\hline
\end{tabular}

\section{Methods}

A sample of 56 community resilience frameworks and assessment methods was gathered by subject matter experts in the areas of community resilience and indicator-based measurement. The frameworks cover a variety of disciplinary perspectives (e.g., economics, urban planning, and engineering) and numerous focal areas (e.g., natural, physical, and/or social systems). Further, these frameworks operate at different spatial scales, are aimed at a variety of audiences, and are at various stages of development and implementation (from those that are entirely conceptual to those that have already been applied). This sample of community resilience frameworks is not an exhaustive list of every resilience indicator or resilience assessment methodology. However, it provides breadth of coverage of units of analysis, hazards, and approaches in the field.

The data entry began by examining the 56 resilience frameworks and categorizing the focal area (or areas) contained within them. Broad, general categories were used rather than a more focused approach to catalog the themes of each framework because this approach enables the comparison of frameworks against each other and it captures the variety of indicators used within each of the 56 frameworks. The focal areas were identified based on a review of each framework and its constituent indicators. The frameworks were then cataloged into seven overarching focal areas, as well as a category for Not clear where no focal area was identified (Table 1).

Table 1. Definitions of focal areas.

\begin{tabular}{|c|c|}
\hline Framework focus & Definition \\
\hline Buildings & Individual building specific \\
\hline Infrastructure & Infrastructure systems of any type \\
\hline Economic & Finances, funding, poverty, etc. \\
\hline Health & Public health, disease, illness, nutrition, access to medical care, etc. \\
\hline Other social & Welfare, politics, social connectedness, community collaboration, etc. \\
\hline Natural & Environment, ecosystems, land, animals, etc. \\
\hline Other & Focal areas other than those listed above \\
\hline Not clear & Focal area is unclear or cannot be determined based on the framework text \\
\hline
\end{tabular}


In the preliminary assessment, Buildings and Infrastructure categories were combined, but it was later determined that the categories needed to be split because some frameworks were focused on infrastructure systems writ large (and included buildings), some were applicable only to buildings. The broad Economic category included everything from public financing, government expenditures, poverty related issues, or other economic concerns. Thus, if the framework had any mention of these economic issues as an indicator focal area, it was included. Likewise, frameworks that touched on any area of population health were included in our Health category which encompassed focal areas of public health, disease or illness rates, ensuring adequate nutrition, and access to medical care, among others. The Other social category was used to bin frameworks that included broad, difficult to measure concepts of social interaction and political dynamics. These included mentions of concepts such as social connectedness, social cohesion, community collaboration activities, and participation in elections. The amount of arable land, animal ownership and husbandry techniques, ecosystem condition, and overall environmental status were components of the Natural category. Frameworks could be categorized by more than one focal area. Any mention of a focal area not captured in any of our defined categories were binned in the Other category. Similarly, if the focal area(s) of a framework were not addressed in the documentation describing it, then it was categorized as Not clear.

Twenty-two categories were developed to catalog the unit of analysis used by each of the 56 frameworks in their resilience assessment. The final units of analysis are detailed in Table 2.

Table 2. Units of analysis.

\begin{tabular}{|c|c|}
\hline Individual & Municipality \\
\hline Household & County \\
\hline Building & Metropolitan area \\
\hline Organization & Intrastate region \\
\hline Tribe & State / territory \\
\hline Parcel & Interstate region \\
\hline Census block & Country \\
\hline Census block group & Global \\
\hline Census tract & Ecosystem \\
\hline ZIP code & Other \\
\hline Community & Not provided \\
\hline
\end{tabular}

The resilience frameworks were also categorized by the hazard type(s) to which they were applicable. Fourteen hazard types were found within the documentation of each framework. The hazards were: climate change/sea level rise; drought; earthquake; three different types of flooding (inland, tsunami, and winddriven surge); hurricane; tornado; wildfire; winter storm; other natural hazards; disease; technological or human-caused hazards; and, terrorism. Frameworks that are not designed to a specific hazard are also included.

Each framework was examined to determine if it had been utilized in a real-world application or was only conceptual in nature. This category was named Status, and each framework was binned accordingly. A Not clear option was also included for those frameworks where there was not enough information to classify it appropriately.

Indicators use quantitative or qualitative data to establish the relative value of a given property in a specific community system, and, if the data is collected over a period of time, indicators can shed light on any direction of change from the initial status [17]. Indicators are often used in combination to create a composite indicator. Composite indicators utilize a variety of indicators coupled with various mathematical methods to arrive at a single value representing a complex relationship [18]. As such, each indicator was categorized according to how they are constructed: it was comprised of multiple measures (a composite indicator) or the indicator consisted of a single measure. The unit of analysis was evaluated for each indicator along with whether the indicator was an input or was an output in the assessment of community 
resilience. For example, input was assigned when the framework specified that the indicator is used to contribute to the development of an overall score, and output was selected when the framework specified that the indicator is the overall score that is derived from the measurement.

Measures are the data used to operationalize the theoretical indicators of the various frameworks. The measures used by the 56 frameworks were characterized in several ways. First, the measures were cataloged across the frameworks in relation to the associated indicator. Then, for each measure, the following information was documented: units of analysis, spatial reporting (i.e., the spatial area for which the measure is gathered), temporal reporting (i.e., how often the measure data is collected), and availability (i.e., if the measure had been collected or if a new collection effort would be required). Additionally, the measure type was recorded (i.e., if the measure was binary, categorical, continuous, etc.), the measure's availability and source location (i.e., if available, where the data can be found), and, if the measure was ultimately transformed into a score of resilience in the framework.

The data entered in the inventory was analyzed using basic descriptive statistics. Section 3.1 describes the results of the framework categorization, Sec. 3.2 describes the results of the indicator categorization, and Sec. 3.3 describes the results of the measure categorization.

\subsection{Description of the frameworks}

The results show that most frameworks include a focus on indicators of Other social and Economic: $96.4 \%(\mathrm{n}=54)$ and $94.6 \%(\mathrm{n}=53)$, respectively. The concentration of indicators in the Other social category is evidence of the reliance on social system indicators when measuring community resilience. When compared to categories such as Buildings or Natural, a social focus was more consistently employed across frameworks. An Infrastructure focus was included in $85.7 \%(\mathrm{n}=48)$ of the frameworks (Fig. 1).

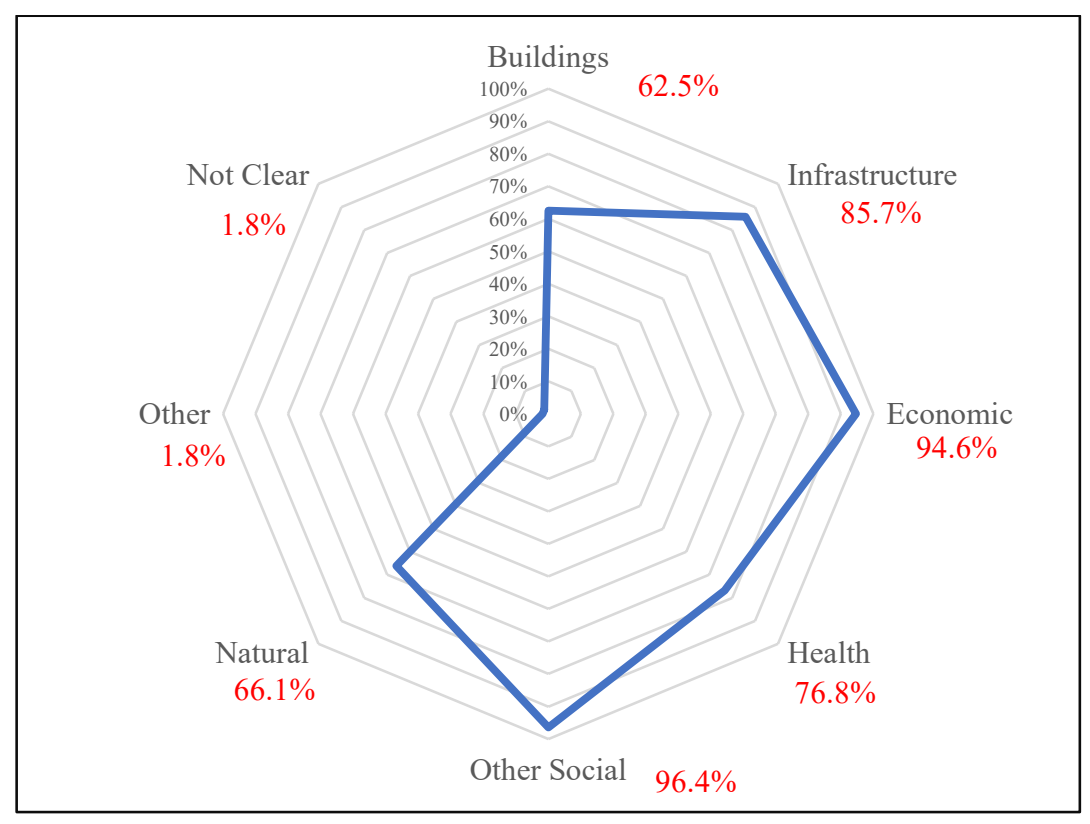

Fig. 1. Focal areas of frameworks. 


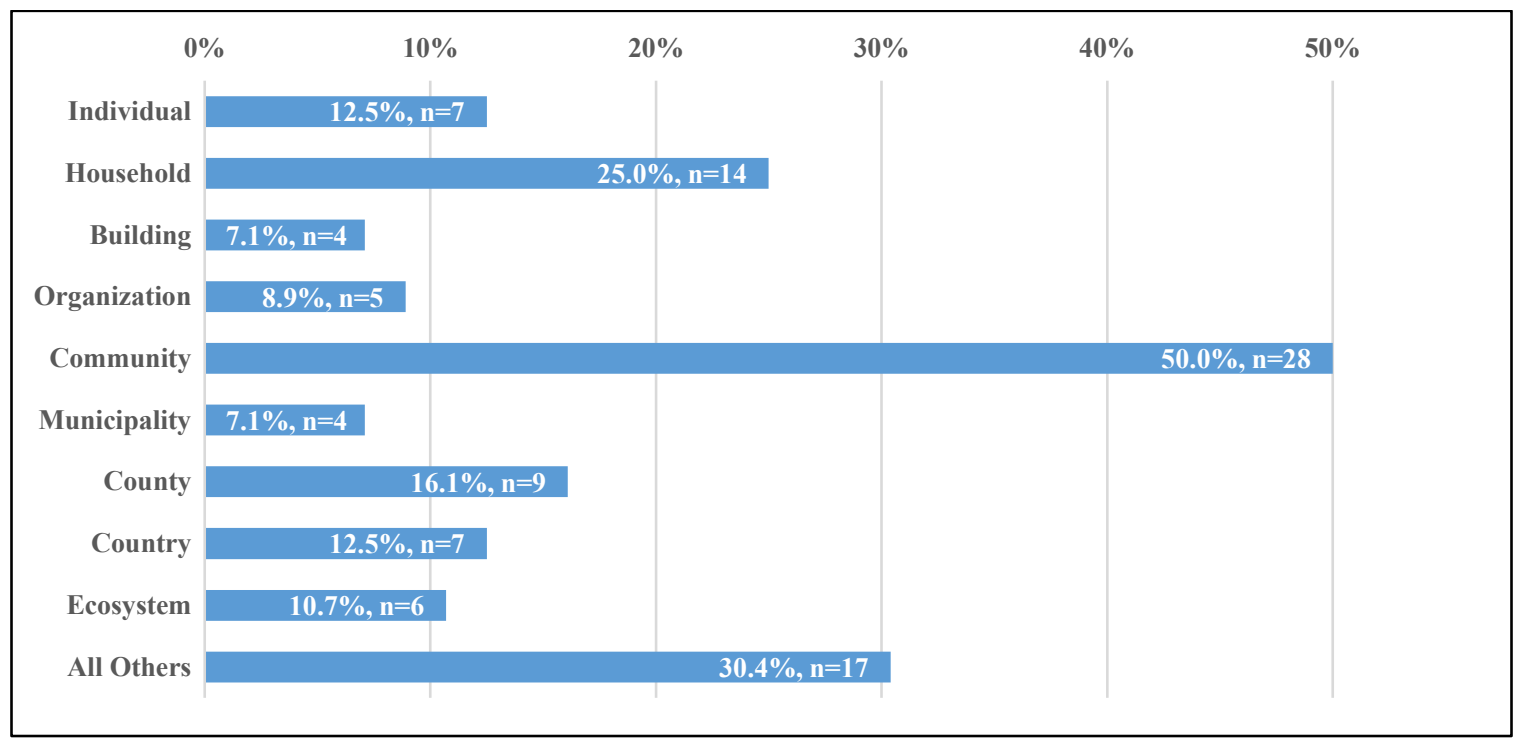

Fig. 2. Units of analysis of frameworks.

Many of the frameworks spanned multiple units of analysis. However, Community and Household units of analysis were the most frequently used by the frameworks, with $50.0 \%(\mathrm{n}=28)$ and $25.0 \%(\mathrm{n}=14)$, respectively (Fig. 2). The County unit of analysis was also commonly used, with a frequency of $16.1 \%$ $(\mathrm{n}=9)$. No frameworks assessed resilience at the Parcel level. Similarly, no frameworks used the US Census block group or ZIP code as a unit of analysis. Unsurprisingly, no frameworks attempted to use a Global unit of analysis. The unit of analysis was not provided in $5.4 \%(\mathrm{n}=3)$ of the frameworks (Fig. 2 and Table 3).

Table 3. The units of analysis for the frameworks.

\begin{tabular}{|c|c|c|c|}
\hline \multicolumn{4}{|c|}{$\begin{array}{c}\text { Counts of units of analysis } \\
\text { No. ( } \% \text { of frameworks utilizing the unit) }\end{array}$} \\
\hline Community & $28(50.0 \%)$ & State/Territory & $3(5.4 \%)$ \\
\hline Household & $14(25.0 \%)$ & Not provided & $3(5.4 \%)$ \\
\hline County & $9(16.1 \%)$ & Tribe & $2(3.6 \%)$ \\
\hline Country & $7(12.5 \%)$ & Census tract & $1(1.8 \%)$ \\
\hline Individual & $7(12.5 \%)$ & Census block & $1(1.8 \%)$ \\
\hline Ecosystem & $6(10.7 \%)$ & Interstate region & $1(1.8 \%)$ \\
\hline Organization & $5(8.9 \%)$ & Census block group & $0(0 \%)$ \\
\hline Building & $4(7.1 \%)$ & Parcel & $0(0 \%)$ \\
\hline Municipality & $4(7.1 \%)$ & ZIP code & $0(0 \%)$ \\
\hline Metropolitan area & $3(5.4 \%)$ & Global & $0(0 \%)$ \\
\hline Intrastate region & $3(5.4 \%)$ & Other & $0(0 \%)$ \\
\hline
\end{tabular}

Figure 3, below, shows that of the 56 frameworks analyzed, $60.7 \%(n=34)$ of the frameworks were applicable to specific hazard events. Many of the frameworks, $37.5 \%(\mathrm{n}=21)$, focused on Inland flood events and $30.4 \%(\mathrm{n}=17)$ focused on Climate change and/or Sea level rise. Approximately twenty-eight percent of the frameworks could be or were applied to the resiliency of Drought events $(\mathrm{n}=16)$ as well as to Other Natural hazards $(\mathrm{n}=16)$. The categories of Earthquake and Technological or human-caused hazards were the focus of $25.0 \%(\mathrm{n}=14$, each) of the frameworks.

Tsunamis and hurricanes were the hazard focus of a smaller proportion of the frameworks in our analysis, at $21.4 \%$ and $19.3 \%$, respectively. Wind-driven surge and Disease each had $16.1 \%(\mathrm{n}=9$, each) of the hazard focus in the frameworks, while $5.4 \%(\mathrm{n}=3$, each) of the frameworks focused on Tornadoes, Wildfire, or Terrorism, individually. And Winter storms were applicable to $3.6 \%(\mathrm{n}=2)$ of the frameworks. 


\section{Journal of Research of the National Institute of Standards and Technology}

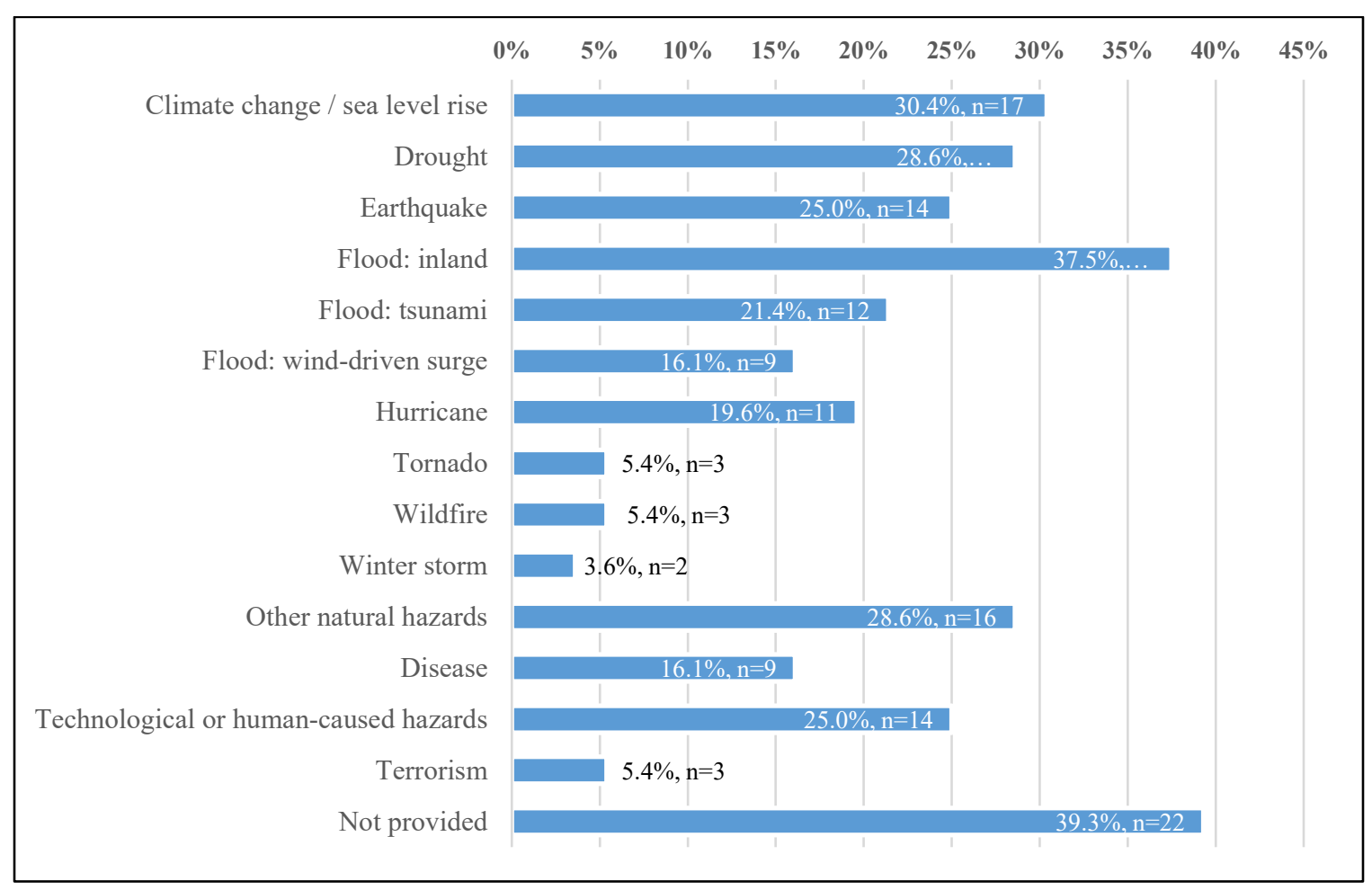

Fig. 3. Hazards of interest in frameworks.

Most of the frameworks, $64.3 \%(\mathrm{n}=36)$, were conceptual (i.e., not yet implemented) while $18(32.1 \%)$ were implemented at some point. Two frameworks had unique categorization: (1) Cutter's Social Vulnerability Index $(\mathrm{SoVI})^{\odot}$ was deemed both conceptual and implemented because the source material includes both a conceptual framework as well as an operational version that has been implemented, and (2) IASC In-Country Team Self-Assessment Tool for Natural Disaster Response Preparedness, where the status could not be determined from the framework's literature (Table 4) ${ }^{1}$.

Table 4. Framework status.

\begin{tabular}{|c|c|}
\hline Status & Count \\
\hline Conceptual & $36(64.3 \%)$ \\
\hline Implemented & $18(32.1 \%)$ \\
\hline Conceptual/implemented & $1(1.8 \%)$ \\
\hline Not clear & $1(1.8 \%)$ \\
\hline
\end{tabular}

When considering the status of the frameworks in relation to the hazard focus, Fig.4 shows that for only three hazards did implemented frameworks outnumber conceptual frameworks: earthquakes, hurricanes, and disease. Eight implemented frameworks, compared to six conceptual frameworks, used an earthquake hazard scenario to develop resilience assessments. The counts of implemented and conceptual frameworks for hurricane and disease focused resilience assessments are closer. Six implemented frameworks and five conceptual frameworks used a hurricane scenario for resilience assessment. And five implemented frameworks and four conceptual frameworks were designed for a disease hazard context. The same pattern continues with inland flooding hazards where 11 resilience assessment frameworks were categorized as conceptual, 9 as implemented, and one as both conceptual and implemented. Finally, of the

\footnotetext{
${ }^{1}$ The researchers decided to not go beyond the primary literature when populating the Inventory.
} 
total of 17 frameworks developed for assessments of resilience to climate change and/or sea level rise, 10 were categorized as conceptual and 7 as implemented frameworks.

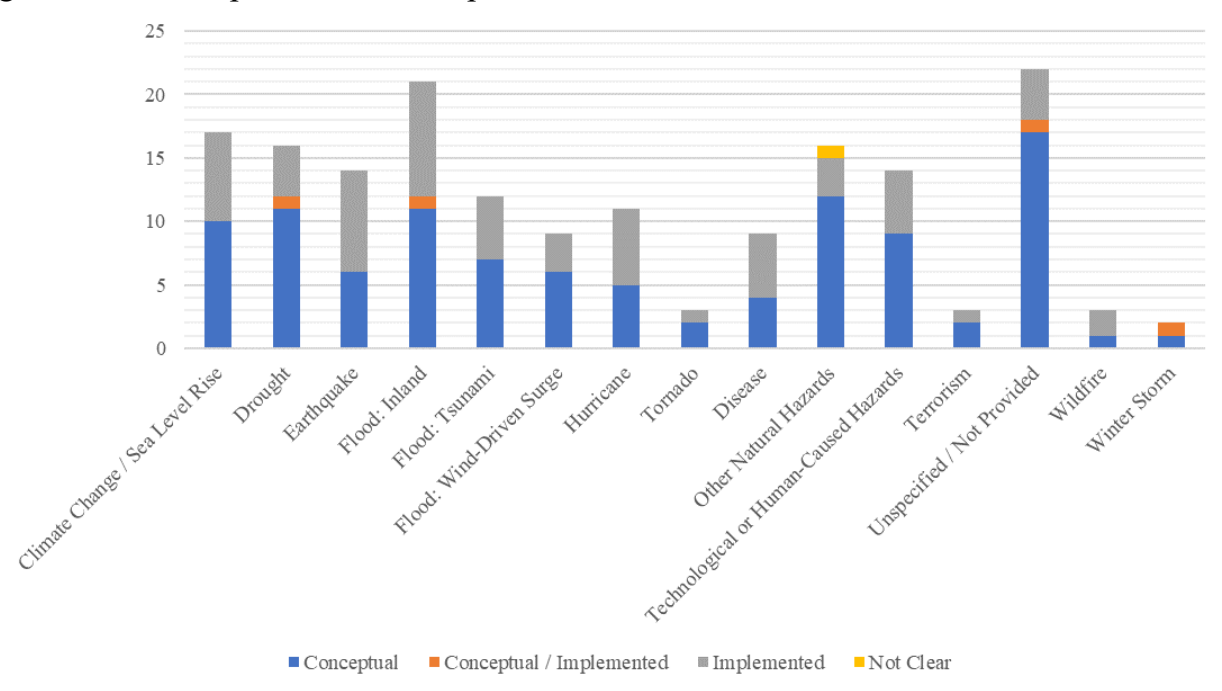

Fig. 4. Crosstabulation results of framework status by hazard focus.

Figure 5 shows that there were six units of analysis where implemented frameworks outnumbered conceptual frameworks: the Census block, metropolitan area, municipality, interstate region, intrastate region, and state/territory. Most of the conceptual frameworks used the community as a spatial unit of analysis $(\mathrm{n}=22)$ which was almost four times higher than the six frameworks that have been implemented used at this level of analysis. The next most used unit of analysis was the household, where 10 conceptual frameworks and 4 implemented frameworks estimated resilience at this level.

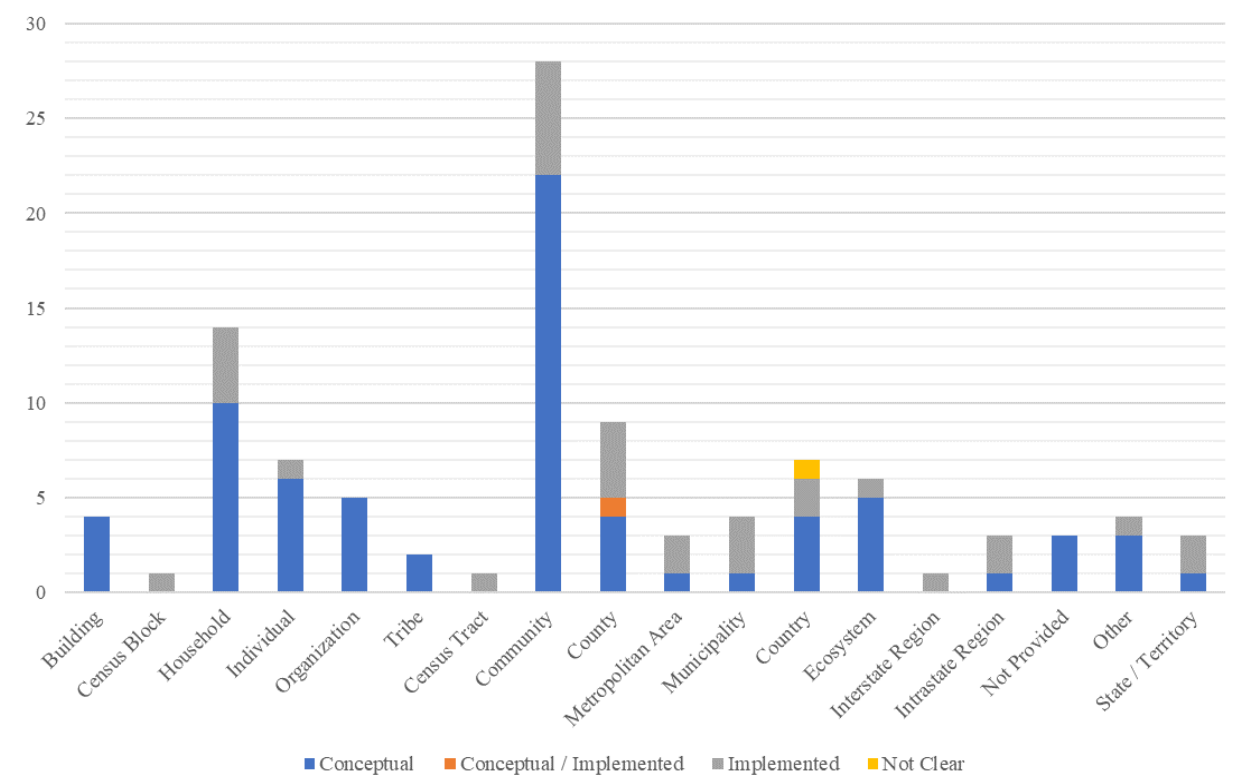

Fig. 5. Crosstabulation results of framework status by unit of analysis. 


\subsection{Description of the indicators}

Looking at the single-measure indicators, the average number of indicators used was approximately 71 per framework. The highest number of single-measure indicators was recorded for HAZUS-MH with 411; the least number was 4 used in the International Institute for Sustainable Development's Climate Resilience and Food Security (IISD) framework. Composite indicators totaled 669 in the inventory out of a total of 3,298. The most composite indicators were used in the Oregon Resilience Plan at 76, while twelve frameworks contained no composite indicators.

Similarly, the indicator units of analysis consisted of single-measure values and averaged approximately 150 per category. This was based on a total of 3,298 indicators across 22 categories. It should be noted that there was a wide variation in the count per category, ranging from a low of 18 for the Project Outcome unit of analysis going up to 1,342 in the Community category. The composite indicators totaled 669 across the same 22 units of analysis categories. The Community category had the highest number of composite indicators at 192, while no composite indicators were used in three units of analysis categories: Census Block, Census Tract, and Census Block Group.

The highest count of indicators of any type was found in the HAZUS-MH framework with 412; the least amount was 5 and found in the 2014 Keating et al. paper titled, "Operationalizing Resilience against Natural Disaster Risk: Opportunities, Barriers, and a Way Forward", referred to as the Zurich Flood Resilience Alliance framework in this analysis.

\subsection{Description of the measures}

There were 7,165 measures used in the 56 frameworks. The HAZUS-MH framework utilized the largest number of measures with a total of 2,050; this number included 1,541 measures collected at the Building or Infrastructure component unit of analysis. The second highest count of measures was within the Oregon Resilience Plan which uses 664, all of which were collected at the Building, Infrastructure component, or the Infrastructure system unit of analysis. The fewest measures were found in the InterAmerican Development Bank Disaster Deficit Index which included 7 single-measure indicators collected at the Country level.

There were more measures of Continuous variable type than any other $(28.1 \%, \mathrm{n}=2,014)$. And while $1,967(27.5 \%)$ measures could not be associated with a specific variable type or were of unspecified type, the remaining measures could be classified as Categorical $(20.3 \%, \mathrm{n}=1453)$, Integer $(15.7 \%, \mathrm{n}=1124)$, or Binary $(8.5 \%, \mathrm{n}=607)$. There were 1,537 measures that ultimately transformed into a score of resilience and 3,865 that were not used as inputs to a resilience score. However, 1,763 measures were Not applicable or Not specified, thus it was not known if they could be used as inputs in calculations of resilience scores.

The time interval of the data collected for a given measure was referred to as Measure Temporal Reporting in the framework inventory. Some of the measure data sets are collected at routine time intervals (e.g., annually, quarterly, monthly), and other data sets are collected for a single time point. An analysis of the temporal reporting of the measures reveals that over $78 \%(\mathrm{n}=5,601)$ had no specified or applicable time frame for measure data collection. The second largest number, 1,356 (18.9\%), was associated with a "onetime" data collection, which generally refers to survey data collection efforts specific to a project. The third most frequent temporal reporting for measures was on an annual basis $(n=80,1.1 \%)$. The remaining data collection periods for the measure reporting are shown in Table 5. 
Table 5. Measure temporal reporting.

\begin{tabular}{|c|c|}
\hline Time interval & Count \\
\hline 5-year average & 1 \\
\hline Annual & 80 \\
\hline Every 4 years & 1 \\
\hline Less freq. than annual & 16 \\
\hline Monthly & 22 \\
\hline Not applicable & 1609 \\
\hline Not specified & 3992 \\
\hline One-time & 1356 \\
\hline Other & 8 \\
\hline Quarterly & 18 \\
\hline Semi-annual & 5 \\
\hline Variable & 57 \\
\hline
\end{tabular}

The geographic unit at which the data for the measure is collected was recorded as Measure Spatial Reporting in the inventory. The geographic unit Community had 1,449 $(20.2 \%)$ instances of measure data being collected at that spatial level. Municipality was the third most frequently cited spatial unit of measure data $(\mathrm{n}=724,10.1 \%)$, followed next by Infrastructure component at $699(9.8 \%)$. It should be noted that 517 , or, $74 \%$ of the 699 Infrastructure component measure data points come from the HAZUS-MH framework. The data for the spatial reporting category was either Not specified ( $\mathrm{n}=166,2.3 \%)$ or Not applicable $(\mathrm{n}=1,494,20.8 \%)$ roughly one fifth of the time. Totals of all measure spatial reporting categories are shown in Table 6.

Table 6. Spatial unit reporting for measures.

\begin{tabular}{|c|c|c|c|}
\hline Spatial unit & Count & Spatial unit & Count \\
\hline Building & 525 & Intrastate region & 591 \\
\hline Census block & 327 & Metropolitan area & 53 \\
\hline Census tract & 224 & Multinational & 724 \\
\hline Community & 1,449 & Municipality & 1,494 \\
\hline Country & 227 & Not applicable & 166 \\
\hline County & 398 & Not specified & 5 \\
\hline Dataset grid & 1 & Organization & 110 \\
\hline Global & 38 & Rural community & 1 \\
\hline Household & 72 & State / territory & (blank) \\
\hline
\end{tabular}

The Measure Unit of Analysis was documented across all 56 frameworks to describe the geographic unit at which the measure data is collected. There are 51 spatial unit categories from the 7,165 measures recorded. The spatial unit of Buildings had a total of 1,157 measures being collected at that scale. It is important to note that 968 (83.6\%) originated from one framework: HAZUS-MH. The spatial scale Community ( $\mathrm{n}=937)$, followed by Infrastructure Component $(\mathrm{n}=935)$ ranked very high. However, as with Buildings, the Infrastructure Component spatial scale was dominated by the HAZUS-MH framework with 537 , or $61.2 \%$ of the total, in that spatial unit. Many measures' spatial unit was categorized as either Not Applicable or Not Specified $(\mathrm{n}=1,694)$. The remaining results can be found in Table 7. 
Table 7. Measure unit of analysis.

\begin{tabular}{|c|c|c|c|}
\hline Measure unit of analysis & Count & Measure unit of analysis & Count \\
\hline Activities & 1 & Intrastate region & 115 \\
\hline Animal & 1 & Jobs & 1 \\
\hline Animals & 1 & Jurisdiction & 1 \\
\hline Area & 4 & Livestock source & 1 \\
\hline Areas & 1 & Local economies & 1 \\
\hline Associations & 1 & Local governments & 2 \\
\hline Building & 1,157 & Markets & 1 \\
\hline Census block & 41 & Mechanisms & 1 \\
\hline Census tract & 30 & Metropolitan area & 11 \\
\hline Coastal habitats & 1 & Municipality & 670 \\
\hline Colleges & 1 & Not applicable & 1,588 \\
\hline Committees & 1 & Not specified & 106 \\
\hline Community & 937 & Organization & 39 \\
\hline Country & 130 & Plant & 1 \\
\hline County & 186 & Programs & 5 \\
\hline Data & 1 & Rangeland & 2 \\
\hline District & 3 & Rural community & 37 \\
\hline Ecosystem & 1 & Schools & 1 \\
\hline Electrical interruptions & 1 & Sectors of society & 1 \\
\hline Farms & 1 & Sector & 1 \\
\hline Governments & 1 & Seed source & 1 \\
\hline Groups & 3 & Services & 1 \\
\hline Household & 250 & Social networks & 2 \\
\hline Individual & 532 & State / territory & 9 \\
\hline Industry & 1 & Storms & 2 \\
\hline Infrastructure component & 935 & Tribe & 4 \\
\hline Infrastructure system & 336 & Universities & 1 \\
\hline Institutions & 1 & (blank) & 1 \\
\hline
\end{tabular}

The final analysis of measures looked at the availability of the measures. That is, whether the data is already routinely collected and if so, at what scale is the measure data found. A total of 2,780 (38.7\%) of the measures require a new collection for each application of the framework as the data is not already available. Among the available measures, 2,399 are collected at the National level and 64 are collected at the International level. The remaining counts for measure availability can be found in Table 8 . 
Table 8. Measure availability.

\begin{tabular}{|c|c|}
\hline Available at: & Count \\
\hline International & 64 \\
\hline National & 2,399 \\
\hline National / not specified & 7 \\
\hline New collection required & 2,780 \\
\hline Non-national government & 2 \\
\hline Not applicable & 1,568 \\
\hline Not specified & 340 \\
\hline Partial & 5 \\
\hline
\end{tabular}

\section{Impact}

This report describes the assembly and analysis of an inventory of community resilience indicators and measures, along with their source framework. It represents one of three products to be released as part of the foundational work to develop, analyze, and document existing frameworks for the purpose of developing a community resilience methodology (see the NIST Community Resilience Group products page for more details: link). The inventory is being used by NIST researchers to assess the current state of the field of resilience measurement; it will provide the basis for ongoing analyses to identify consensus in the use of indicators for resilience. If many frameworks use the same indicator or measure, it may indicate a general acceptance in the resilience assessment community as to the utility of that measure or indicator. Alternately, it may indicate that the data are easily collected and therefore, the indicator is less resource intensive. Either way, the indicator can be further tested to examine its properties and value for resilience measurement. NIST researchers envision the inventory as beneficial to academic researchers and practitioners, as well as other community stakeholders, as they work to understand the many community resilience measurement methods available. This report, coupled with other forthcoming products, provides a ready resource for these groups to make use of existing frameworks for tailoring a methodology to assess their community's resilience, activities such as supporting grant application preparation, or for furthering research in the resilience assessment space.

The inventory has several potential uses and intended audiences. Examples of the types of uses are discussed by audience type below.

Academic researchers may find the inventory useful for further exploring and analyzing the space of resilience measurement. The dataset represents an extensive review in terms of the total number of indicators included and of the dimensions assessed at the framework and indicator/measure levels. Because the attributes are composed of lower-level themes or constructs, researchers will have the opportunity to advance the work by expanding the dimensions included in the evaluation. And because methods utilized in assembling this inventory are extensible across measures and focal areas, new frameworks and methodologies can be added. In fact, researchers are encouraged to expand the number of frameworks within the inventory by downloading and updating the inventory with the entry of new frameworks as they become available. In this way, the inventory will continue to grow and change to support various lines of inquiry related to resilience indicators and assessment methodologies. Likewise, NIST researchers plan to evaluate the need to issue an updated version of the inventory every three years, given the state of the field of community resilience assessment.

Practitioners such as municipal managers, planners, and other government officials can use the data filtering options in the inventory as a tool to identify methodologies that are specifically applicable to the focal area, the needs of the community, the intended use of the assessment, and resources available. For example, by searching for frameworks that will focus on a particular system, at a specific spatial scale, and are geared toward a specific hazard, practitioners can identify options and evaluate the level of technical skill and resources required to implement a particular assessment methodology. 
Other community stakeholders may find benefit in use of the specific indicators and measures in the inventory. When applying for grants that require some form of monitoring and evaluation a community representative could search for existing indicators for resilience related characteristics and/or outcomes for which data are already available to meet guidelines. Furthermore, community stakeholders may use the indicator inventory as a source of key performance indicators for a range of plans including floodplain management plans, hazard mitigation plans, and economic development plans, thereby allowing community stakeholders to tailor a methodology to assess their community's resilience that best suits their needs and specific context.

\section{Acknowledgments}

The authors would like to acknowledge the generous support of our internal NIST reviewers for their timely and beneficial comments and recommendations. We would also like to thank Sarah Morgan, our NIST Summer Undergraduate Research Fellow, who contributed to additional data cleaning and analysis of the inventory. The NIST authors also recognize that the analyses presented herein would not have been possible without the hard work and dedication from Frank Lavelle, Charles Goodhue, and the team of researchers with Applied Research Associates, Inc. and Eastern Research Group, Inc. Finally, the authors thank the members of the project team for their ongoing commitment to the important work ahead.

\section{References}

[1] Parker DJ (2020) Disaster resilience - a challenged science. Environmental Health 19(1):1-9. http://doi.org/10.1080/17477891.2019.1694857

[2] Alexander DE (2013) Resilience and disaster risk reduction: an etymological journey. Nat. Hazards Earth Syst. Sci. 13:27072716. https://doi.org/10.5194/nhess-13-2707-2013, 2013

[3] Rose AZ (2009) Economic Resilience to Disasters. Published Articles \& Papers Paper 75. http://research.create.usc.edu/published_papers/75

[4] Mayunga JS (2007) Understanding and Applying the Concept of Community Disaster Resilience: A Capital-Based Approach. Paper presented at the 2007 Summer Academy of the Munich Re Foundation.

[5] American Psychological Association (APA) (2020) Building your resilience. Available at https://www.apa.org/topics/resilience

[6] McAllister T D (2013) Developing Guidelines and Standards for Disaster Resilience of the Built Environment: A Research Needs Assessment. NIST Technical Note 1795 (National Institute of Standards and Technology, Gaithersburg MD).

[7] PPD-8 (2011) Presidential Policy Directive, PPD-8 - National Preparedness (The White House, Washington DC). Available at http://www.dhs.gov/presidential-policy-directive-8-national-preparedness

[8] PPD-21 (2013) Presidential Policy Directive, PPD-21 - Critical Infrastructure, Security, and Resilience (The White House, Washington DC). Available at http://www.whitehouse.gov/the-press-office/2013/02/12/presidential-policy-directive-criticalinfrastructure-security-and-resil

[9] Lavelle FM, LA Ritchie, A Kwasinski, B Wohlson (2015) Critical Assessment of Existing Methodologies for Measuring or Representing Community Resilience of Social and Physical Systems. NIST Grants/Contractor Reports 15-1010 (National Institute of Standards and Technology, Gaithersburg MD). https://doi.org/10.6028/NIST.GCR.15-1010

[10] Kwasinski A, J Trainor, B Wohlson, FM Lavelle (2016) A Conceptual Framework for Assessing Resilience at the Community Scale. NIST Grants/Contractor Reports 16-001 (National Institute of Standards and Technology, Gaithersburg MD). https://doi.org/10.6028/NIST.GCR.16-001

[11] Kwasinski A, J Trainor, R Francis, C Chen, FM Lavelle (2017) Further Development of a Conceptual Framework for Assessing Resilience at the Community Scale. NIST Grants/Contractor Reports 17-013 (National Institute of Standards and Technology, Gaithersburg MD). https://doi.org/10.6028/NIST.GCR.17-013

[12] Koliou M, JW van de Lindt, T McAllister, BR Ellingwood, M Dillard, H Cutler (2020) State of the research in community resilience: progress and challenges Sustainable and Resilient Infrastructure 5(3):131-151. http://doi.org/10.1080/23789689.2017.1418547

[13] Edgemon, L, C Freeman, C Burdi, J Trail, K Marsh, K Pfeiffer (2018) Community Resilience Indicator Analysis: County-Level Analysis of Commonly Used Indicators from Peer-Reviewed Research. Available at https://www.hsdl.org/?view\&did=828573

[14] Bakkensen, LA, C Fox-Lent, LK Read, I Linkov (2017) Validating Resilience and Vulnerability Indices in the Context of Natural Disasters. Risk Analysis 37:982-1004. http://doi.org/10.1111/risa.12677

[15] Shafari A (2016) A critical review of selected tools for assessing community resilience. Ecological Indicators 69:629-647. 
[16] Winderl T (2014) Disaster resilience measurements: stocktaking of ongoing efforts in developing systems for measuring resilience. United Nations Development Program.

[17] Freudenberg, M (2003) Composite Indicators of Country Performance: A Critical Assessment. OECD Science, Technology and Industry Working Papers, No. 2003/16 (OECD Publishing, Paris, France). https://doi.org/10.1787/405566708255

[18] Saisana, M, S Tarantola (2002) State-of-the-art report on current methodologies and practices for composite indicator development. Report EUR 20408 EN (European Commission-Joint Research Centre, Ispra, Italy).

About the authors: Jarrod Loerzel is a Research Social Scientist in the Community Resilience Program
within the Materials and Structural Systems Division at NIST.
Maria K. Dillard is a Research Social Scientist in the Community Resilience Program within the
Materials and Structural Systems Division at NIST.
$\quad$ The National Institute of Standards and Technology is an agency of the U.S. Department of Commerce. 